\title{
Electrochemical Impedance Spectroscopy for Microbial Fuel Cell Characterization
}

\author{
Narendran Sekar and Ramaraja P Ramasamy* \\ Nano Electrochemistry Laboratory, College of Engineering, University of Georgia, Athens, USA
}

\begin{abstract}
Electrochemical impedance spectroscopy is an efficient, non-intrusive and semi-quantitative technique to characterize the performance of bio-electrochemical systems such as microbial fuel cells and enzymatic fuel cells. Indeed, quantitative interpretation of the impedance data can be obtained with the help of mechanistic models using meaningful equivalent circuits. The production of maximum power using such systems has been limited by their higher internal resistance. The contribution of several different resistances to the overall internal resistance of the system can be ascertained through the measurement of impedance using EIS, which is greatly required for understanding and engineering of its principle components leading to better enhancement of its performance. EIS has been successfully employed in most of the MFC researches helping in advancement of the field through emergence of many novel MFC designs with greater power generating capacity. In a nutshell, impedance spectroscopy provides a valuable addition to the existing biochemical and spectroscopic techniques to better optimize the electrochemical behavior of the biological system.
\end{abstract}

Keywords: Electrochemical impedance spectroscopy; Microbial fuel cell; Anode impedance; Cathode impedance; Full cell impedance

\section{Introduction}

Bio-electrochemical energy conversion using biological fuel cells has been recently emerging as a sustainable and renewable technology for energy technology for portable remote power generation applications. Biological Fuel Cells (BFCs) use biological catalysts (e.g. microbes, enzymes) for the catalysis of electrochemical reactions. Besides significant performance improvements in BFCs over the past few years (in terms of power density, robustness etc), several fundamental challenges still exist. Understanding of the issues and challenges is critical in the further advancement of this technology for practical applications. This necessitates the use of potent characterization tools to study these systems to extract information that will lead to the understanding of the fundamental challenges. Such an understanding will enable BFC researchers to design systems that could overcome the fundamental challenges. There has been quite a bit of literature on BFCs on aspects such as cell design, reaction mechanisms, operational conditions and system limitations. However there has not been enough focus on the appropriate electrochemical techniques for biological fuel cell diagnostics in the available literature. Also there is no detailed literature on any particular technique specifically for BFC diagnostics. This article comprehensively reviews the use of electrochemical impedance spectroscopy for biological fuel cell characterization.

\section{Biological Fuel Cells}

Over the years there have been two types of biological fuel cells, microbial based and enzymatic based. Recently a third type of biological fuel cell has been emerging which is based on photosynthetic organelles [1-7]. By the sheer number of articles published in the literature, number of researchers working in the field of microbial fuel cells (MFCs) vastly outnumbers both enzymatic and photosynthetic fuel cells. Microbial electrolyzers function similar but opposite to that of microbial fuel cells where electrical energy is used to generate a chemical product [8]. There have not been any significant attempts in system level studies in both enzymatic and photosynthetic fuel cell when compared to MFCs or microbial electrolyzers. Accordingly the electrochemical impedance spectroscopy technique has not been explored in great detail for these systems. In this review, we restrict our discussion of EIS within the context of microbial fuel cells. The mini-review by He and Mansfeld [9] explored the use of EIS in MFCs, whereas this review sheds light on the characterization of MFCs using EIS comprising the research works published thereafter until now. Another critical review by Dominguez-Benetton et al. [10] explains elaborately on the use of graphical methods for improving EIS analysis and the constant phase elements parameters. Overall, we present here a review updated on the most recent findings regarding EIS in the study of microbial fuel cells from a clearly different perspective avoiding redundancy as much as possible.

Microbial Fuel Cells (MFCs) are devices that use micro-organisms such as bacteria as catalysts to oxidize organic and inorganic matter and generate electricity [11-14]. The electrons generated during the oxidation of these substrates by the bacteria are captured by the anode and then transferred to the cathode via the external circuit which results in the generation of electricity under load (resistor). The microbial catalysts employed in the MFCs are called exo-electrogens, which are capable of transferring the electron extracellularly to their immediate vicinity, i.e., the anode which acts as an alternate electron acceptor. The transfer of electron to the anode surface can take place in two different ways - 1) direct electron transfer by biofilm forming bacteria such as Geobacter sp. which transfer electrons through proteins on their cell surface called outer membrane cytochromes and/or through some specialized appendages called pili or nanowires; 2) mediated electron

*Corresponding author: Ramaraja P Ramaswamy, Nano Electrochemistry Laboratory, College of Engineering, University of Georgia, Athens, GA 30602 USA, Fax: 1-706-542-3804; E-mail: rama@uga.edu

Received May 30, 2013; Accepted July 11, 2013; Published July 15, 2013

Citation: Sekar N, Ramasamy RP (2013) Electrochemical Impedance Spectroscopy for Microbial Fuel Cell Characterization. J Microb Biochem Technol S6: 004. doi:10.4172/1948-5948.S6-004

Copyright: (c) 2013 Sekar N, et al. This is an open-access article distributed unde the terms of the Creative Commons Attribution License, which permits unrestricted use, distribution, and reproduction in any medium, provided the original author and source are credited 
transfer i.e., some bacteria such as Shewanella sp. secretes mediators (flavins) which shuttle the electrons from bacteria to the anode surface.

In MFCs, the voltage generated depends on various factors such as the rate of transfer of electron from the bacteria to anode, diffusion of substrate into the biofilm, ohmic resistance of the electrolyte and other electrochemical kinetics. Accordingly, the design of the MFCs has been improving continuously to overcome the physical constraints of the device such as operating conditions, electrode spacing, etc. [15], but the ultimate factor to be considered is the bacterial metabolism and the electron transfer rates at either electrodes. The basic technology, challenges and the applications of microbial fuel cells have been reviewed extensively in several articles $[11,16]$. The main reason for varied difference in the MFC setup designed so far is the internal resistance of the reactor, compared to the intrinsic resistances due to the kinetic and mass transport effects. Thus MFC setup has been viewed as the design with current passing through two resistors connected in series, one being the external load connected and the other being the internal resistance of the system. So the maximum power generated by a MFC depends on the total internal resistance of the system. Such internal resistance of a MFC can be evaluated by methods such as current interrupt, polarization slope method or power density peak methods. The above methods require the MFC to be a simple resistive unit (that obeys Ohm's law), whereas in reality a MFC impedance would consist of contributions from individual resistances due to activation kinetics, charge transfer, double layer charging, mass transport effects and ionic resistance. Moreover, these individual contributions do not remain constant, but vary depending on the operating conditions and have pronounced effect on the performance of MFCs. But the dynamic response of the system cannot be measured using the aforementioned current interrupt or polarization slope methods. This calls for alternate methods for the analysis of individual resistances in MFCs.

\section{Characterization Tools}

Investigation of biological fuel cells can be carried out using a variety of surface, analytical, spectroscopic, biochemical and electrochemical characterization techniques. The choice is a particular tool depends on the property of MFC to be investigated. Morphological (surface) characterization techniques such as scanning electron microscopy (SEM), fluorescent microscopy, confocal laser scanning microscopy (CLSM) are useful in the characterization of microbial biofilm on the anode surface of MFCs in order to understand the growth patterns, biofilm density, heterogeneity and thickness of the biofilm. They are also useful in studying the porosity of the electrode and membrane materials used in MFC. The substrate utilization, product composition and extracellular mediators in the MFC anolyte can be detected and analyzed by a variety of biochemical, spectroscopic and electrochemical methods. Biochemical methods such as redox mediator assays are quantitative and help in measuring the concentration of the redox mediators, while spectroscopic methods such as UV-VIS, LC-MS and HPLC are also highly useful in identifying and subsequently quantifying the chemical species. On the other hand electrochemical techniques such as cyclic voltammetry $(\mathrm{CV})$, differential pulse voltammetry (DPV) are qualitative, help in identifying the components responsible for electron shuttling in the form of current peaks based on their reversible electrochemical activities. CV has been extensively used in the characterization of the biological-fuel cells where mediated electron transfer is the predominant mechanism of electron transfer [17]. The secretion of flavins by Shewanella sp. and their role in extracellular electron transfer have been identified with the help of CV and their concentrations were then quantified using chromatographic techniques [17]

Increasingly often, analysis based on another electrochemical technique namely electrochemical impedance spectroscopy (EIS) is now being used. In voltammetry, by imposing potential steps or sweeps, the electrode is driven to a condition far from equilibrium and the response will be observed which a transient signal is usually. However, in EIS, the system is perturbed with an alternating current of small magnitude and the way the system follows the response is studied at steady state. Another significant advantage of impedance measurements is that the technique is non-intrusive or non-destructive, i.e., it can be performed in the operating MFC without disturbing the system, whereas other characterization tools discussed above require the MFC need to be disturbed and the samples are being collected for subsequent analyses. Hence, EIS is a steady state electrochemical technique where the measurements are made without altering the current-voltage properties of the biological fuel cell system. EIS has also been widely used in various areas of electrochemical research such as corrosion [18,19] and fuel cells [20]. Further, EIS is a useful tool to investigate the contribution of different internal resistances to the overall impedance of the fuel cells [21-27].

\section{Basics of Impedance}

The importance of impedance is significant and appreciable especially in a highly heterogeneous system such as MFCs. The electrochemical interface of MFC is highly complex where the microbes colonize the electrode, making the electrochemical reaction intricate. Electrochemical Impedance Spectroscopy (EIS) is a powerful method to investigate the dynamics of the bound or mobile charges in the bulk or interfacial region of such system. The basics and fundamental theory of impedance are discussed in the following section.

\section{Fundamental theory}

According to Ohm's law, resistance $(R)$ is defined as the ratio of voltage $(V)$ to current $(I)$ and is a measure of opposition to the passage of electric current through the conductor. Besides the normal resistance, there are two other mechanisms impeding the current flow in the electrical circuit: the induction of voltages in the conductor selfinduced by the magnetic fields of current called inductance $(L)$ and the electrostatic storage of charge induced by voltage between conductors called capacitance $(C)$. The inductance and capacitance are together called the reactance $(X)$. The concept of resistance has been extended to the quantity called impedance $(Z)$ in the AC circuit. Whereas, the DC signal can be defined as analogous to the AC signal at the frequency tending to zero. The ideal resistance possesses only magnitude whereas the impedance possesses both the magnitude and the phase angle and is usually represented in the form of a complex number. The unit of impedance is the same as that of resistance, which is ohm $(\Omega)$. In the complex plane, the real part of impedance is resistance and the reactance forms the imaginary part of the impedance.

Thus for a sinusoidal current or voltage input, the magnitude of the complex impedance is the ratio of voltage amplitude to the current amplitude, whereas, the phase angle of the complex impedance is the phase shift by which the current is ahead of voltage.

\section{Representation of impedance}

The magnitude and the phase angle of the complex impedance can be easily represented with the help of phasor diagram representing the magnitude of the impedance vector as $|Z|$ and the phase angle as $\theta$. 
The magnitude of the impedance can be expressed in terms of real and imaginary components as given in Equation (1).

$$
|Z|=\sqrt{Z_{r}^{2}+Z_{j}^{2}}
$$

and the phase angle can be obtained as given in Equation 2.

$$
\theta=\tan ^{-1}\left(\frac{Z_{j}}{Z_{r}}\right)
$$

Nyquist plot and Bode plot are commonly used to represent the impedance measurement as shown in the Figure 1. In the Nyquist plot, the real part of the impedance is represented in the $\mathrm{x}$-axis and the imaginary part of the impedance is represented in the y-axis and each point in the Nyquist plot corresponds to impedance at one frequency. One major limitation in the Nyquist plot is that the frequency cannot be ascertained by simply looking at the plot. This limitation has been overcome in the Bode plot, where the impedance is plotted with the logarithmic frequency plotted on the $\mathrm{x}$-axis and both the absolute value of impedance and the phase angle are plotted on the y-axis.

\section{Electrical circuit elements}

EIS data is commonly analyzed by fitting into an equivalent electrical circuit model. Most of the circuit elements in the model are common electrical elements such as resistors, inductors and capacitors. The impedance response of such ideal resistors, inductors and capacitors are given below.

$$
\begin{aligned}
& Z_{R}=R \\
& Z_{L}=j \omega L \\
& Z_{C}=\frac{1}{j \omega C}
\end{aligned}
$$

The impedance of an ideal resistor will be purely real and the current through the resistor will be always in phase with the voltage across it, whereas, the impedance of an ideal inductor and capacitor will be purely imaginary. The impedance versus frequency response of an inductor will be opposite to that of a capacitor. An inductor's impedance increases as the frequency is raised whereas the capacitor's impedance decreases with an increase in frequency.

EIS models usually consist of a number of elements connected in the network either in series and/or parallel combinations. For a highly nested electrical circuit, the equivalent impedance is calculated by lumping together the simple circuits.
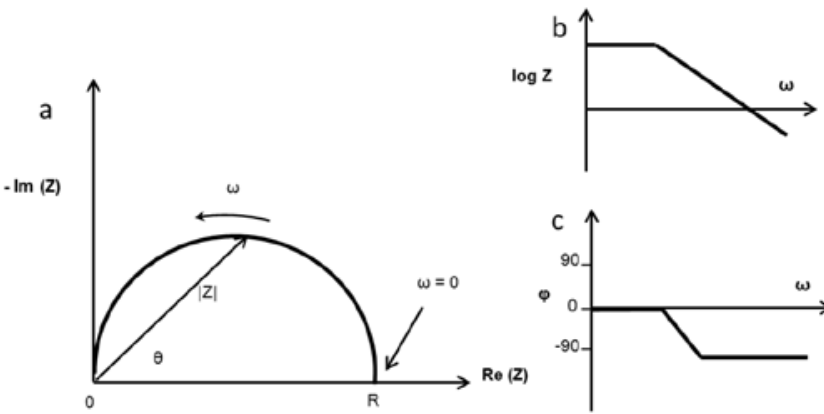

Figure 1: Representation of EIS data in (a) Nyquist plot, (b) Bode plot and (c) phase angle plot.

\section{Electrochemical parameters relevant to impedance}

Electrolyte resistance: In an electrochemical cell, the resistance offered by the ionic solution (electrolyte) is an important factor contributing to the overall impedance of the cell. The resistance of the ionic solution depends on type of ions, ionic concentration, temperature and the geometry of the projected area across which the current is carried and is defined by Equation 6 .

$$
R=\rho \frac{l}{A}
$$

where ' $\rho$ ' is the resistivity of the solution and is more commonly expressed as its reciprocal term called conductivity $(\kappa)$, ' $l$ ' is the length and ' $A$ ' is the area of the object containing the solution. Determination of the current flow path and the geometry of the electrolyte solution are important parameters to be considered in calculating the conductivity of the electrolyte. Nevertheless, the microorganisms in solution can also contribute to the electrolyte resistance [28]. Accordingly this can be addressed by proposing two resistances in parallel at the electrolyte level. One resistance corresponds exclusively to the nature of electrolytic medium and the second resistance specifically concerning the resistance due to microorganisms. But it is of not a major concern here, since the electrolyte resistance can be calculated by fitting the EIS to an equivalent electrical circuit model.

Double layer capacitance: A charge separation or electrical double layer exists at any interface in the polarized system such as the interface between the electrode and the electrolyte, ion exchange membranes, etc., which is equivalent to a capacitor in the electrical circuit. Similarly, charge separation also occurs across the bacterial membrane to maintain the proton motive force for their energy metabolism [29]. The formation of biofilm on the electrode surface can have a pronounced effect on the thickness of double layer, which in turn influences the double layer capacitance of the system. The value of double layer capacitance depends on various factors such as electrode polarization, ionic concentration, temperature, type of ions, oxide layers; roughness of the electrode, etc. On a bare metal immersed in an electrolyte, 20-60 $\mu \mathrm{F}$ of capacitance can be measured for every $1 \mathrm{~cm}^{2}$ of the electrode. For carbon based materials, the capacitance ranges anywhere from 30 to $200 \mu \mathrm{F} / \mathrm{cm}^{2}$ [30]. More recently Malvankar et al. [31] reported direct measurement of in-vivo capacitance of G. sulfurreducens biofilm and demonstrated that the pseudo-capacitance has been conferred upon by the c-type cytochromes on the bacterial outer membrane such as $\mathrm{OmcB}, \mathrm{OmcE}, \mathrm{OmcS}$ and OmcT. Further, it is interesting to note that a high capacitance of around $3500 \mu \mathrm{F}$ has been measured with $100 \mathrm{mV}$ amplitude voltage excitation for the wild type G. sulfurreducens DL-1 strain, which contain several different outer-membrane cytochromes [31]. The expression for double layer capacitance has been developed by many models such as Helmholtz's model, Guoy-Chapman model, Stern model and Grahame model which can be found elsewhere [23].

Polarization resistance: The electrode is said to be polarized if the applied electrode potential $\left(E_{a p p}-E_{o c}\right)$ is different from the equilibrium potential of the electrochemical reaction at the polarized electrode leading to oxidation/reduction of the species at the electrode surface. For the two simple kinetically controlled reactions occurring, the potential of the cell is related to the current as defined by the ButlerVolmer related, a simplified version of which is given by Equation 7 .

$$
I=I_{\text {corr }}\left[e^{\frac{2.303\left(E-E_{O C}\right)}{\beta_{a}}}-e^{\frac{-2.303\left(E-E_{O C}\right)}{\beta_{c}}}\right]
$$


Where $I$ and $I_{\text {corr }}$ are the measured cell current and the corrosion current respectively, $\beta_{a}$ and $\beta_{c}$ are anodic and cathodic Beta coefficients (V/decade). But applying a small signal approximation to the above equation, the corrosion current can be obtained as given in Equation 8 .

$$
I_{\text {corr }}=\frac{\beta_{a} \beta_{c}}{2.303\left(\beta_{a}+\beta_{c}\right)}\left[\frac{1}{R_{P}}\right]
$$

The above equation incorporates a term $R_{p}$ called polarization resistance. Thus the current can be calculated by knowing the polarization resistance and the Beta coefficients.

Charge transfer resistance: The transfer of electron from the ionic species in the solution to the solid metal is called charge transfer reaction, which depends on the kind of the reaction, temperature, concentration of the reactants and the potential. The general relation between the potential and current relating the amount of electrons and charge transfer is given by Equation 9 .

$$
i=i_{0}\left[\frac{C_{o}}{C_{o}^{*}} \exp \left(\frac{\alpha z F \eta}{R T}\right)-\frac{C_{R}}{C_{R}^{*}} \exp \left(\frac{-(1-\alpha) z F \eta}{R T}\right)\right]
$$

Where $i_{0}$ is the exchange density, $C_{O}$ is the concentration of the oxidant at the electrode surface and $C_{O}{ }^{*}$ is the concentration of the oxidant in the bulk, $C_{R}$ is the concentration of the reductant at the electrode surface, $C_{R}{ }^{*}$ is the concentration of the reductant in the bulk, $z$ is the number of electrons involved, $\alpha$ is the reaction order, $F$ is the Faraday constant, $\eta$ is the over-potential, $T$ is the temperature and $R$ is the gas constant. When the concentration at the electrode surface is equal to that at the bulk, the equation simplifies to the following form (Equation 10) called Butler-Volmer equation, which is applicable when the polarization depends only on the charge transfer kinetics, i.e., for a completely stirred system.

$$
i=i_{0}\left[\exp \left(\alpha \frac{z F}{R T} \eta\right)-\exp \left(-(1-\alpha) \frac{z F}{R T} \eta\right)\right]
$$

When the over-potential $(\eta)$ is very small and the electrochemical system is at equilibrium, the expression for the charge transfer resistance is given by Equation 11 .

$$
R_{C T}=\frac{R T}{z F i_{0}}
$$

If $R_{C T}$ is known, the exchange current density $\left(i_{0}\right)$ can be calculated from this equation.

Diffusion: Diffusion plays a greater role in mass transport processes from the bulk electrolyte through the biofilm. The substrates have to diffuse through the biofilm, get oxidized and the products formed have to diffuse back to the bulk electrolyte. Such diffusion is appreciable only at the lower AC frequency, whereas at a higher $\mathrm{AC}$ frequency the impedance due to diffusion is negligible, since the reactants would not have enough time to move from bulk to the surface for the electrochemical reactions. Accordingly the impedance created by this diffusion phenomenon requires incorporation of a diffusion element in the equivalent circuit model. The element representing the semi-infinite linear diffusion is called Warburg impedance, whereas the finite diffusion can be represented by $\mathrm{O}, \mathrm{T}$ and $\mathrm{G}$ elements $[23,32,33]$. The equation for finite diffusion $\mathrm{O}$ element $\left(Z_{0}\right)$ is given by Equation 12 .

$$
Z_{O}=\sigma \omega^{-\frac{1}{2}}(1-j) \tanh \left[\delta\left(\frac{j \omega}{D}\right)^{1 / 2}\right]
$$

$$
\begin{aligned}
& \text { Where } \\
& \sigma=\frac{R T}{n^{2} F^{2} A \sqrt{2}}\left[\frac{1}{C_{O}^{*} \sqrt{D_{O}}}+\frac{1}{C_{R}^{*} \sqrt{D_{R}}}\right]
\end{aligned}
$$

$\omega$ is the radial frequency, $\delta$ is the Nernst diffusion layer thickness, $D$ is the average value of diffusion coefficients of the diffusing species, $D_{O}$ is the diffusion coefficient of the oxidant, $D_{R}$ is the diffusion coefficient of the reductant and $A$ is the surface area of the electrode.

Similarly finite diffusion T element $\left(Z_{T}\right)$ through a film with a fixed amount of electro-active species (e. g. batteries and superconductors) is given by Equation 14 .

$$
Z_{T}=\sigma \omega^{-\frac{1}{2}}(1-j) \operatorname{coth}\left[\delta\left(\frac{j \omega}{D}\right)^{1 / 2}\right]
$$

If the diffusion thickness is infinite, the diffusion element given in Equation 12 simplifies to Warburg impedance $\left(Z_{W}\right)$ as given in Equation 15.

$$
Z_{w}=\sigma \omega^{-\frac{1}{2}}(1-j)
$$

The Warburg impedance appears as a diagonal line with a slope of $45^{\circ}$ on the Nyquist plot and exists with a phase shift of $45^{\circ}$ on the Bode plot.

Further, quantitative information such as diffusion co-efficient of the electro-active species can be calculated from the modeled diffusional impedance data using Equation 12, which eventually help to ascertain the comprehensive validation of the equivalent circuit model.

\section{Equivalent Circuit Models}

A metal surface covered with smooth, undamaged coating generally has very high impedance. The equivalent circuit for such an undamaged metal surface consists of a resistance $(R)$ in series with a simple capacitance $(C)$ and is called purely capacitive coating. The corresponding Nyquist plot for such an ideally polarized electrode will have a straight vertical intersecting the $\mathrm{Z}^{\prime}$-axis and the $\mathrm{X}$-intercept gives the value of resistance. But practically, due to the contamination and roughness of the electrode, the straight line can be observed intersecting the $Z^{\prime}$ axis at an angle smaller than $90^{\circ}$. The corresponding phase angle given by $\theta_{c}=-(1-\beta) \pi / 2$ is assumed to be independent of frequency and is called constant phase angle. The value of dimensionless quantity $\beta$ varies from 0 to 1 . Accordingly the $C_{d l}$ will be replaced by CPE (constant phase element) in the equivalent circuit. Most rough surfaces and porous electrodes (such as MFC biofilm) will use CPE instead of an ideal capacitor.

A simplified Randles circuit is one of the most commonly used cell models and a starting point for other complex models. The simplified Randles cell consists of a solution resistance, double layer capacitance and a charge transfer or a polarization resistance. The double layer capacitance $\left(C_{d l}\right)$ is in parallel with the charge transfer resistance $\left(R_{C T}\right)$ and this parallel combination is in series with the ohmic resistance $\left(R_{\Omega}\right)$ as shown in the Figure 2a. This is simply equivalent to a metal electrode dipped in the electrolyte. The corresponding Nyquist plot contains a semicircular arc intersecting the real axis (Z') at two places as shown in Figure $2 \mathrm{~b}$. The intercept closest to the origin gives the value of solution resistance $\left(R_{\Omega}\right)$ and the intercept farthest from the origin gives the value of total resistance $\left(R_{\Omega}+R_{C T}\right)$. Similarly the inclusion of Warburg 
element to this simplified Randles cell result in a semicircle with one extended arm as shown in Figure $2 \mathrm{c}$ and $2 \mathrm{~d}$.

Similarly, more complex model can be developed based on the physical characterization of the electrode such as partially blocked electrode, electrode coated with an inert porous layer, completely porous electrode, electrode coated with multiple layers of inert porous layers, etc., which are very well explained by Orazem and Tribollet [23] and in the former reviews on EIS [10,34].

\section{EIS Measurement}

EIS measurement is a simple procedure usually conducted with the help of a Frequency Response Analyzer coupled to a potentiostat. The frequency range usually varies from $100 \mathrm{KHz}$ to $1 \mathrm{mHz}$ and a small $\mathrm{AC}$ signal of amplitude 5 or $10 \mathrm{mV}$ is usually applied to analyze the current response of MFC without disturbing its operation. Such small signal will not create a large over-potential to disturb the system [26]. The MFC can be connected to the potentiostat either in two-electrode or threeelectrode mode. The three-electrode mode is employed to analyze the individual impedance (anode impedance or cathode impedance). In such cases, for measuring the anode impedance, anode is the working electrode, cathode acts as counter electrode and the reference electrode $(\mathrm{Ag} / \mathrm{AgCl})$ can be placed near the anode. Similarly when cathode is the working electrode, anode as the counter electrode and the reference electrode $(\mathrm{Ag} / \mathrm{AgCl})$ near the cathode can be useful for the measuring cathode impedance. For the measurement of full cell impedance, twoelectrode mode is used where one electrode serves as working electrode and the alternate electrode can serve as both the counter and reference electrode, which does not require a separate reference electrode. However such measurements assume that the potential of counter/ reference electrode does not vary during measurement which is far from practical for the case of MFCs. Impedance spectra are usually collected at the potential of OCV or different applied potentials based on the necessity of the testing conditions under study.

\section{MFC Impedance}

The total power output of the MFC is limited by its high internal resistance which necessitates the analyses of the various components of internal resistance and their contribution to the overall internal
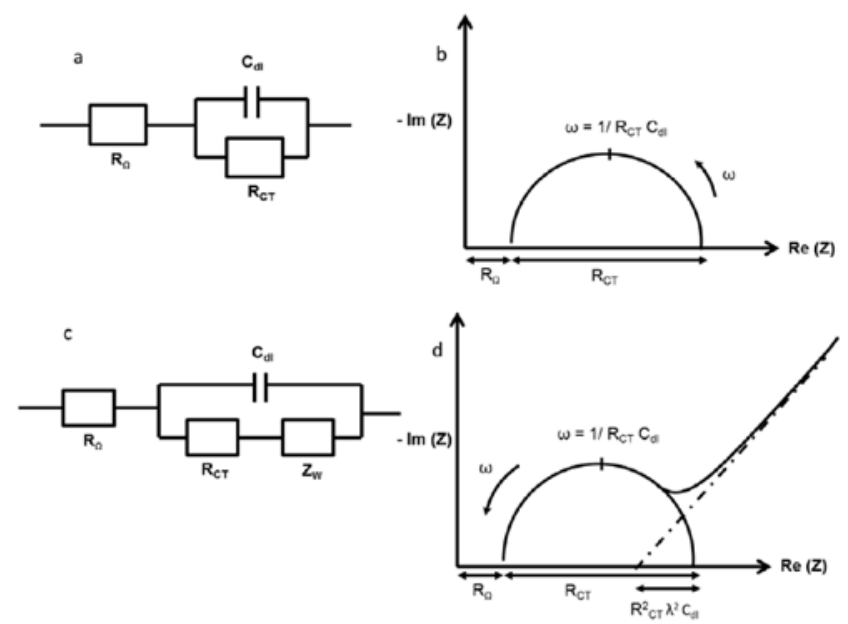

Figure 2: (a) Representation of Randles circuit, (b) its characteristic Nyquist plot, (c) Randles circuit with Warburg element and (d) its characteristic Nyquist plot. resistance and adoption of suitable methodologies to overcome them are very important criteria to be considered to enhance the performance of MFC.

The flow of current due to the transfer of electron across the electrified interface contains both faradaic (current flow results in an electrochemical reaction) and a non-faradaic (current flow does not result in electrochemical reactions) components. The faradaic component arises from the electron transfer across the interface by overcoming an appropriate activation barrier namely the polarization resistance $\left(R_{p}\right)$ and ohmic resistance $\left(R_{\Omega}\right)$. The non-faradaic current arises from charging the double layer capacitor at the interface which incorporates a double layer capacitance $\left(C_{d l}\right)$. The ohmic resistance is contributed by resistance due to electrolyte solution, proton exchange membrane and other connections. In contrast to the nearly ideal $R_{\Omega}$ and $C_{d l}$ the faradaic component $R_{p}$ is not ideal and changes with the frequency. The polarization resistance includes the charge-transfer limited activation losses $\left(R_{a c t}\right)$ and diffusion-limited concentration losses $\left(R_{\text {conc }}\right)$. Charge transfer resistance is the major kinetic limitation due to slow activation reaction rates on both the anode and the cathode. The charge transfer at the interface also affects the mass transport of the reactant and the product; thereby incorporating diffusion limited resistance. Both the charge transfer resistance and the diffusion resistance occur at the interface between the electrode surface and the surrounding electrolyte $[22,35]$. Thus the internal resistance can be written as Equation 16.

$$
R_{\text {int }}=R_{\Omega}+R_{p}^{a}+R_{p}^{c}
$$

The above equation can further be expanded to Equation 17 by including both the activation $\left(R_{\text {acc }}\right)$ and concentration polarization $\left(R_{\text {conc }}\right)$ of the anode and the cathode [10].

$$
R_{\text {int }}=R_{\Omega}+R_{\text {act }}^{a}+R_{\text {act }}^{c}+R_{\text {conc }}^{a}+R_{\text {conc }}^{c}
$$

The various factors that affect the internal resistance of the MFC include different types of substrates used in the anode chamber, types of electron acceptors, mediators, concentration of electrolyte buffers used, geometry and design of the reactor, etc., Several studies have revealed that the configuration of anode, cathode and the PEM were found to significantly affect the internal [15,36-40].

Since the past decade, EIS has been employed to determine each of these components of internal resistance with the help of equivalent electrical circuit models and the knowledge of which can be addressed specifically to optimize the design of MFC leading to enhanced power output of the system [41,42]. Extensive literature for the usage of EIS in optimizing MFC has been reviewed in the following section in three different categories as anode impedance, cathode impedance and impedance of the full cell. The effect of substrates, mediators, buffers, electrode materials on anode and cathode impedances and the effect of geometry and cell design on impedance of the full cell has been discussed elaborately. Table 1 summarizes the studies conducted by the researchers to analyze the effect of various factors on the impedance of anode, cathode and the full cell using EIS.

\section{Half-cell Systems}

\section{Anode impedance}

Influence of bacterial biofilm: The anode polarization resistance of the anode is a major component of the internal resistance of the MFC. Development of biofilm on the anode surface significantly decreases 
anode charge transfer resistance indicating their catalytic role in the transfer of electron to the anode as reported in multiple reports [41,4345]. Manohar et al. [44] used EIS to evaluate the electrochemical properties of the MFC harboring S. oneidensis MR-I where the anode polarization resistance decreased significantly from $7790 \mathrm{k} \Omega$ to $10.2 \mathrm{k} \Omega$ due to the formation of bacterial biofilm on the anode compared to the control MFC without the bacteria. The other internal resistances including the polarization resistance of the cathode, ohmic resistance of the electrolyte and double layer capacitance were almost stable and remained constant in their observations. Further, the anode charge transfer resistance is the major contribution to the total internal resistance of the MFC, and is lower for MFC that contained microbial biofilm [44]. Similarly in a study conducted by He et al. [46] to evaluate the effect of $\mathrm{pH}$ on anodic and cathodic reactions in air-cathode MFC, the anodic bacterial activity was found to be optimal at the neutral $\mathrm{pH}$ under which the polarization resistance of the anode was also found to be the least compared to other conditions tested. Moreover, Borole et al. [47] observed a reduction in anode impedance from $296.1 \Omega$ to $36.3 \Omega$ in the first 43 days in a compact, flow through porous electrode chambered MFC coupled to air cathode, harboring enriched microbial consortia on the anode and finally to $1.4 \Omega$ at a final external load of 50 $\Omega$ with further enrichment as shown in Table 2.

Nevertheless, the initial bacterial growth rate and its characteristic biofilm formation rate also determine the MFC performance which can be evidenced from the measurement of anode charge transfer resistance of the MFC by Ramasamy et al. [41]. It has been demonstrated that as bacteria grow on the anode surface, the anode charge transfer resistance decreases with time thereby reducing the activation barrier, enhancing the power density during initial phase of bacterial growth in the MFC [41]. Figure 3 shows the Nyquist plot of the anode impedances measured at different time courses such as day 1 , day 5 and 3 weeks with decreasing anode polarization resistance. Further Ren et al. [43] demonstrated that the anode charge resistance reduced from $9 \mathrm{k} \Omega-\mathrm{cm}^{2}$ on $3^{\text {rd }}$ day to $2.5 \mathrm{k} \Omega-\mathrm{cm}^{2}$ after two weeks as a result of gradual development of biofilm on the surface of anode. All these studies confirmed the fact that the anode charge transfer resistance is greatly influenced by the micro-biota growing on the anode surface.

In addition to the charge transfer resistance, it is noteworthy that other impedance parameter called double layer capacitance can be

\begin{tabular}{|c|c|c|c|c|c|}
\hline Impedance & Study & MFC Set up & Anode & Cathode & References \\
\hline \multirow{6}{*}{$\begin{array}{l}\text { Anode } \\
\text { Impedance }\end{array}$} & Biofilm growth & Two chamber & Bare Graphite felt & Bare Graphite felt & [44] \\
\hline & Biofilm growth & Single/ Air-cathode & Carbon felt (porous) & Carbon felt (porous) & [46] \\
\hline & Impact of initial biofilm growth & Two chamber & Carbon paper & Carbon paper & [41] \\
\hline & $\begin{array}{l}\text { Time-course correlation of biofilm } \\
\text { properties }\end{array}$ & Single/ Air-cathode & Carbon paper & Carbon paper & [43] \\
\hline & Effect of mediators & Single + Two & Carbon paper & Carbon paper & [42] \\
\hline & Effect of $\mathrm{pH}$ on anodic reactions & Single/ Air-cathode & Graphite felt & Carbon cloth & [51] \\
\hline \multirow{7}{*}{$\begin{array}{l}\text { Cathode } \\
\text { Impedance }\end{array}$} & Effect of substrate & Single + Two & Carbon paper & Carbon paper & [42] \\
\hline & Effect of substrate diffusion & Two chamber & $\begin{array}{c}\text { Reticulated Vitreous Carbon } \\
\text { Foam }\end{array}$ & Reticulated Vitreous Carbon Foam & {$[55]$} \\
\hline & Effect of mediators & Single + Two & Carbon paper & Carbon paper & [42] \\
\hline & Effect of different cathode materials & Single/ Air-cathode & Carbon felt & $\mathrm{Pt}, \mathrm{Mn}_{2} \mathrm{O}_{3}$ and $\mathrm{Fe}_{2} \mathrm{O}_{3}$ on Carbon paper & {$[57]$} \\
\hline & Effect of different cathode materials & Single/ Air-cathode & Graphite felt & $\begin{array}{l}\text { Graphite felt, Carbon paper, Stainless } \\
\text { steel mesh }\end{array}$ & [58] \\
\hline & Effect of cathode binding agent & Single/ Tubular & Carbon granules & Catalyst layer and Carbon fiber & [59] \\
\hline & Characterization of Bio-cathode & Two chamber & Graphite paper & Graphite paper & {$[64]$} \\
\hline \multirow{6}{*}{$\begin{array}{l}\text { Full Cell } \\
\text { Impedance }\end{array}$} & Reactor configuration & Single/ tubular air-cathode & Carbon granules & Carbon cloth & {$[67]$} \\
\hline & Reactor configuration & Single/ Tubular/ Upflow & Granular activated Carbon & Granular activated Carbon & [22] \\
\hline & Reactor configuration & Floating MFC & Carbon granules & Catalyst layer and Carbon fibre & [68] \\
\hline & $\begin{array}{l}\text { Effects of ionic strength of anode } \\
\text { fluid }\end{array}$ & Single/ Air-cathode & Carbon cloth & Carbon cloth & [69] \\
\hline & Effect of separators & Single/ Air-cathode & Graphite fibre brush & Carbon cloth & [70] \\
\hline & Electron transfer mechanism & Two chamber & Carbon cloth & Carbon cloth & [71] \\
\hline
\end{tabular}

Table 1: Summary of literature on the use of electrochemical impedance spectroscopy for microbial fuel cells.

\begin{tabular}{|l|c|c|c|c|c|c|}
\hline & Day 24 & Day 43 & Day 61 & Day 68 & Day 130 & Day 136 \\
\hline $\mathbf{R}_{\text {anode }}$ & 296.1 & 36.3 & 5.77 & 3.15 & 1.41 \\
\hline $\mathbf{R}_{\text {total }}$ & 299.8 & 48.6 & 18.2 & 17.9 & 1.88 & 16.6 \\
\hline
\end{tabular}

Table 2: Changes in anode and total impedances during a 173-day period in the flow-through porous air-cathode MFC [46] 
correlated to the biofilm formation. Kim et al. [48] has studied the influence of attached bacteria and biofilm on double layer capacitance using EIS. Moreover, Malvankar et al. [31] has observed the increase in double layer capacitance of the G. sulfurreducens biofilm by two orders of magnitude over the capacitance of the electrode without the bacteria and demonstrated that the ability of electron conduction through the biofilm could have been attributed to a network of conductive pili of $G$. sulfurreducens.

Effect of mediators: Some bacteria are well known for their synthesis of endogenous mediators, which act as electron shuttles facilitating the transfer of electron between the bacteria and the anode. This has been particularly observed in the microbial communities where few organisms adhere to the anode surface for direct electron transfer, while others secrete soluble mediators for electron transfer. Shewanella sp. are well known for this type of mediated electron transfer [49-51]. EIS has also been successfully exploited to analyze the response of such mediators to a low amplitude AC signal over mid-frequency ranges. Ramasamy et al. [42] had observed a response in the mid frequency region in EIS which was attributed to the charge transfer resistance $\left(R_{E S}\right)$ of the endogenously synthesized mediators (Figure 4). Due to their low concentration in the anolyte, the charge transfer resistance offered by these mediators was low even though the mediated redox processes possess high electron transfer rate. $R_{A}$ corresponds to the charge transfer resistance for the anode and $R_{\text {other }}$ was correlated with the charge transfer resistance of other metallic salts in the electrolyte, which is present in the control as well.

The addition of mediators to the anolyte decreases the charge transfer impedance for the substrate oxidation and enhances the kinetics of electron transfer from the substrate to the anode. Study conducted by Ramasamy et al. [42] witnessed these finding by observing a reduction in the magnitude of the low frequency Nyquist arc after the addition of $5 \mu \mathrm{M}$ riboflavin to the anolyte which corresponds to the charge transfer impedance for the oxidation of substrate $\left(R_{A}\right)$ (Figure 5). Further it has been concluded that the redox process involving the mediators are 10-15 times faster than the bio-electrochemical oxidation of substrate which is the rate limiting step on the anode [42].

Effect of electrolyte $\mathrm{pH}$ : The $\mathrm{pH}$ of the electrolyte used in the MFC greatly influences the power output of the system. The electrolyte $\mathrm{pH}$ affects the bacterial growth on the anode compartment and most of the bacteria grow well at neutral $\mathrm{pH}$ of 7 . Even though bacteria tolerate a mild variation of neutral $\mathrm{pH}$, but highly acidic and alkaline environment

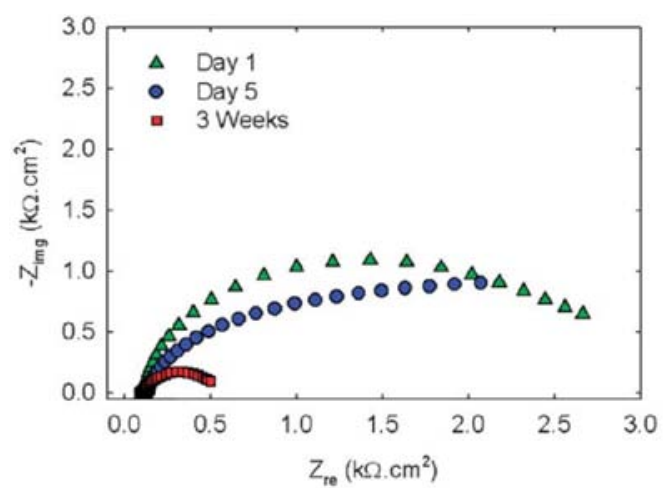

Figure 3: Nyquist plot of the anode impedance for two-chamber MFC on days 1,5 and 3 weeks of an established biofilm [41].

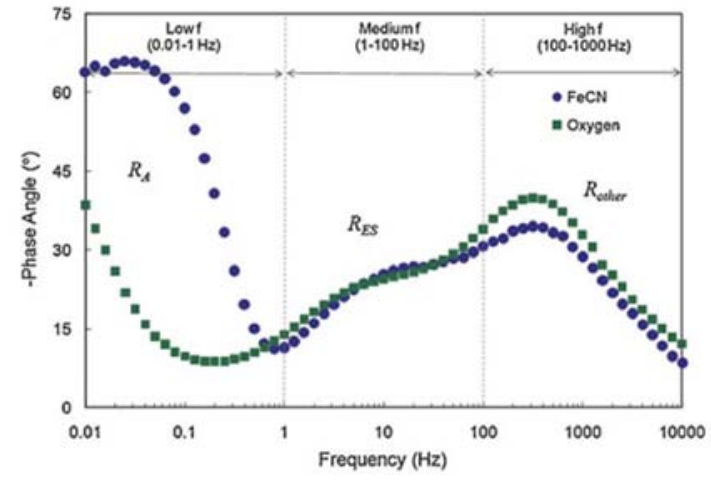

Figure 4: Bode phase angle plots of the anode for potassium ferricyanide (FeCN) and oxygen based MFCs [42].

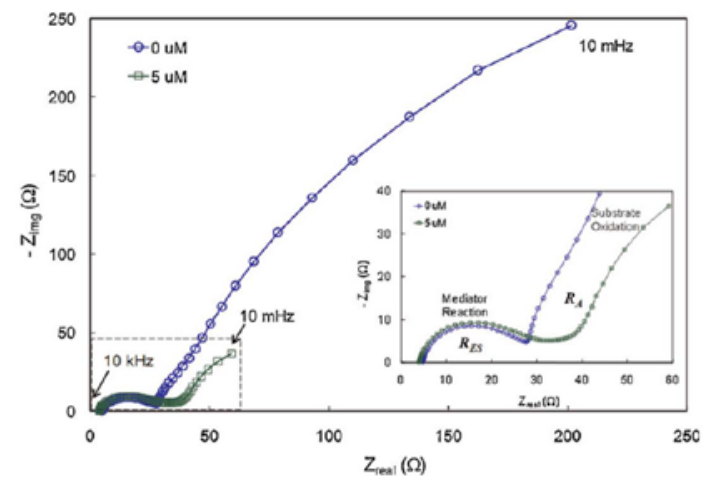

Figure 5: Nyquist plots of the anode impedance before and after addition of riboflavin $(5 \mu \mathrm{M})$ to anolyte. Inset graph show the expanded view of the boxed region [42].

greatly impair their growth and energy generating mechanism [51,52]. On the other hand, the rate of oxygen reduction is favored at alkaline $\mathrm{pH}$ in the electrolyte in the cathode compartment. The MFC tends to maintain different levels between the anode and cathode chambers, which together determine the power output of MFC. For air-cathode MFC, a trade-off between the $\mathrm{pH}$ levels for bacterial growth and oxygen reduction reaction is required for achieving better power output. He et al. [46] evaluated the effect of electrolyte $\mathrm{pH}$ on the rate of the anodic and cathodic reaction in air-cathode MFC using EIS in $\mathrm{pH}$ range between 5 and 10. It was observed that the polarization resistance of the anode $\left(R_{p}^{a}\right)$ has decreased from $\mathrm{pH}$ of 5 , reaching the minimum at $\mathrm{pH} 7$ and then increased further beyond $\mathrm{pH} 8$ until $\mathrm{pH}$ of 10 , which could be well correlated with the typical growth parameter of the bacteria on the anode. Similarly the cathodic reaction was enhanced with increasing $\mathrm{pH}$ and the polarization resistance of the cathode $\left(R_{p}^{c}\right)$ has been found to be decreasing for the entire range of $\mathrm{pH}$ conditions tested [46].

\section{Cathode impedance}

Effect of substrate type: Oxygen is considered to be the most suitable electron acceptor due to its higher redox potential, low cost, availability, sustainability, and lack of chemical waste product. It is also the most feasible reductant for large-scale practical applications [16]. Further when $\mathrm{O}_{2}$ is used as the reductant in MFCs, the system does not require a separate cathode compartment; instead the cathode can be just kept open to air and the system is called air-cathode MFC. The major limitations are the poor diffusion and solubility of oxygen 
leading to very slow kinetics of its reduction reaction at electrode. However, in a single chambered MFC with a rotating cathode, He et al. [53] has observed an increase in polarization resistance of the anode. Even though, the oxygen diffusion can be enhanced by such suitable modifications, it was found detrimental for the bacterial metabolism on the anode in a single chambered MFC. On the other hand, potassium ferricyanide has been extensively employed as catholyte in the laboratory scale two-chambered MFC which produces 1.5 to 1.8 times more power than that of Pt-catalyst-dissolved oxygen reactor [54]. Further, ferricyanide has low over-potential using a carbon paper, resulting in the cathode working potential close to its OCV. However, the greatest disadvantage of ferricyanide is that it needs to be replaced regularly which limits its practical usage in large scale MFC. The electrochemical kinetics of the two systems can be typically analyzed with the help of EIS. Ramasamy et al. [42] has observed that the charge transfer resistance of the cathode with ferricyanide has been lesser compared to that of oxygen suggesting that the ferricyanide reduction is a faster than oxygen reduction reaction (Figure 6). The onset of second arc for the oxygen corresponds to the higher impedance of the oxygen reduction compared to the reduction of ferricyanide. However, the measurement impedance was also influenced by the mass transfer effects [42].

Effect of substrate diffusion: The diffusion of oxygen to the cathode surface for its reduction is of major concern in MFCs with aerated-cathode due to the coupled gas diffusion and solubilization in the electrolyte. The diffusion limitation which has been incorporated in the form of Warburg element in the equivalent electrical circuit model can contribute significantly to the overall internal resistance in such systems affecting the overall power output [41,54]. Lepage et al. [55] included such a Warburg component in the EIS equivalent circuit model to characterize the MFC designed using reticulated carbon foam electrodes with microbial consortia at the anode and aerated cathode system. Figure $7 \mathrm{a}$ depicts the equivalent circuit model used by Lepage et al. [55] to fit the cathode impedance containing series combination of ohmic resistance $\left(R_{s \beta}\right)$, a parallel $R_{1}-C P E_{1 \beta}$ and a generalized finite Warburg element in its short circuit version $\left(R_{\beta}-W_{\beta} \| C P E_{\beta}\right)$. The Warburg element has been included, since the major limitations in the MFC design is the diffusion of oxygen from the electrolyte to the hydrophobic carbon surface. It was also confirmed that the resistance of cathode compartment mainly contributed to the overall resistance of the cell (Figure $7 \mathrm{~b}$ ). In addition to such a higher resistance, the contribution of the oxygen diffusion is attested by the Warburg

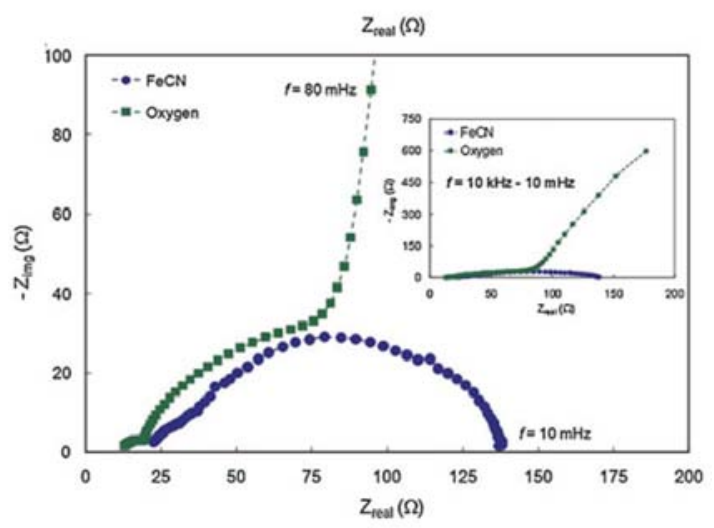

Figure 6: Nyquist plots of the cathode for potassium ferricyanide ( $\mathrm{FeCN})$ and oxygen based MFCs [42]. a
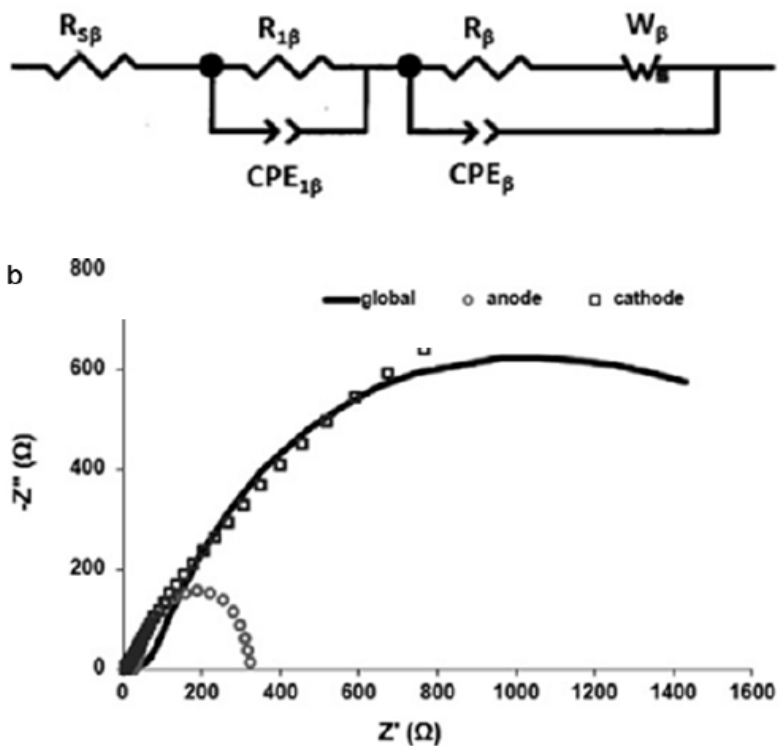

Figure 7: (a) Equivalent circuit model with Warburg element used by Lepage et al. and (b) Nyquist plots of the impedance of the full cell (global) together with the contributions of the anode and the cathode [55]

element with resistance $R_{w}$ of $2.99 \mathrm{k} \Omega \mathrm{cm}^{2}$ and time $\tau_{w}$ of $16.4 \mathrm{~s}$ [55]. This phenomenon has also been witnessed by Kim et al. [56].

Effect of mediators: The mediators are secreted by the bacteria in the anode compartment, which facilitates the electron transfer from the bacteria to the anode. The cathode compartment is spatially separated by the cation exchange membrane (CEM), so diffusion of mediators from the anode compartment to the cathode compartment necessarily depends on the permeability of the CEM used in the MFC. If nafion is used as CEM, it is impermeable to any mediators produced in the anode compartment and those mediators do not have any effect on the cathodic reaction. Whereas, filter membranes are sometimes used in the place of PEM, which allow the transport of small molecules can have pronounced effect on the cathodic reduction reaction. The mediators can facilitate the electron transfer in the cathode half-cell. The concentration, electrochemical properties of the mediators and the cathodic potential highly influence the effect of mediators on the EIS response. Ramasamy et al. [42] studied the effect of mediators on the cathode impedance in two different MFC setups such as ferricyanide cathode with nafion and oxygen cathode with filter membrane and clearly pictures a distance response for the effect of mediators using EIS. Figure 8 shows the Bode plot for the ferricyanide cathode contained only two time constants corresponding to the metal salts in the electrolytes at high frequency region and ferricyanide reduction in the medium frequency region. Whereas, the Bode plot for the oxygen cathode contained three time constants corresponding to oxygen reduction at low frequency region, metal salts in the electrolytes at high frequency region and a significant time constant at the medium frequency region, which was correlated with the charge transfer impedance of the mediators [42].

Effect of cathode material type: The type of cathode material is of greater importance in terms of stability, cost and electrochemical feasibility for scaling up of the MFC particularly in the case of air- 
cathode MFC. The different cathode material imparts different activation resistances for the oxygen reduction reaction that can be quantitatively captured by their EIS response. Martin et al. [57] compared the different cathode materials such as $\mathrm{Pt}, \mathrm{Fe}_{2} \mathrm{O}_{3}, \mathrm{Mn}_{2} \mathrm{O}_{3}$ and carbon to investigate better oxygen reduction reaction in the air-cathode MFC. The EIS analyzes revealed that the charge transfer resistance of the cathode for the materials tested are $4.4 \Omega, 3.6 \Omega, 4.1 \Omega$ and $18.1 \Omega$ respectively. The total cathode impedance also followed the same trend and it has been concluded that Pt cathode showed better oxygen reduction reaction compared by the metal oxides and carbon [57]. More recently, Zhang et al. [58] evaluated the bio-cathode material in MFC by comparing the graphite felt, carbon paper and stainless steel mesh using EIS as shown in Figure 9. It has been observed that charge transfer resistance of the cathode $\left(R_{c t}\right)$ was maximum for stainless steel mesh $(\sim 820 \Omega)$, followed by carbon paper $(23 \Omega)$ and the graphite felt $(11 \Omega)$ and concluded that the graphite felt bio-cathode exhibited the best catalytic behavior towards oxygen reduction reaction [58].

Effect of cathode binding agent: The performance of MFC is greatly influenced by the method of assembling the membrane and the electrode. Nafion solution, perfluorinated ion-exchange solution is often used as a binding agent to connect the Pt particle, membrane and the carbon electrode $[14,44,55]$. EIS was employed by Huang et al. [59] to investigate the performance of MFC with and without Nafion as cathode binding agent and found that the power output of the MFC without Nafion was higher compared to that with Nafion. This was also reflected in the EIS response of the both the MFCs studied as shown in Figure 10. The Bode plot shows that the impedance of cathode with Nafion (NC) was higher than that of without Nafion (WC) for both the exposure times tested. It was also concluded that the impedance of cathode for both NC and WC decreased with exposure time due to increased porosity of the surface layers covering the cathode materials [59].

\section{Characterization of Bio-cathode}

The oxygen reduction reaction at the cathode is still one of the main limiting factors in the performance of MFC in spite of much improvement in the progress of efficient catalyst for the cathodic oxygen reduction [60]. Recently, development of oxygen reducing bio-cathodes is advancing since the micro-organisms are cheap and renewable catalyst for cathodic oxygen reduction [60-62]. In such bio-cathode

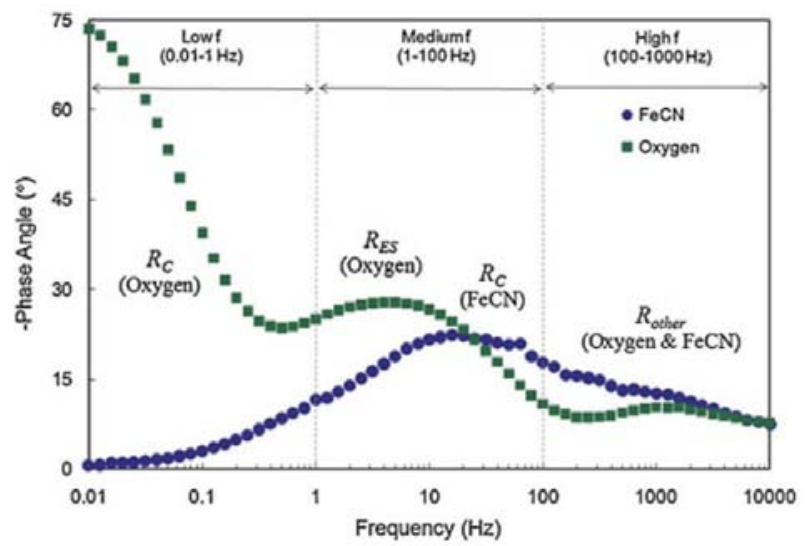

Figure 8: Bode phase angle plots of the cathode for potassium ferricyanide (FeCN) and oxygen based MFCs [42].

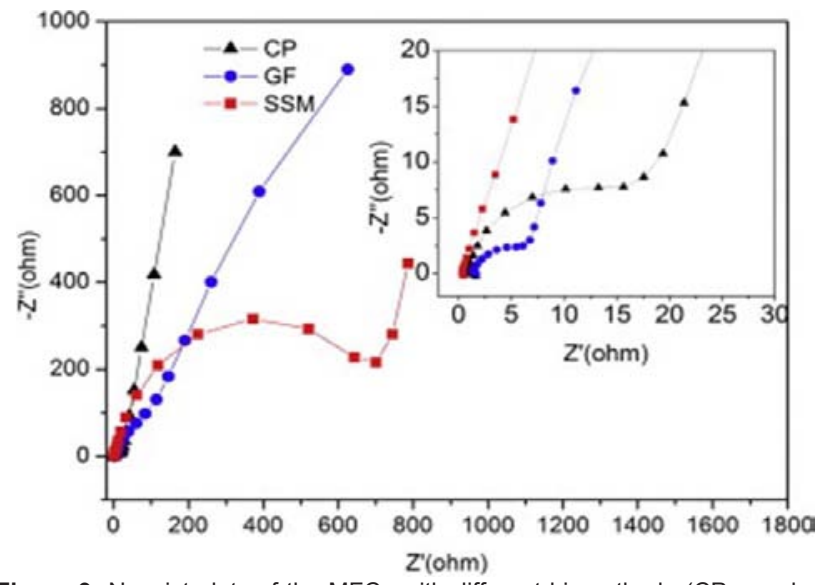

Figure 9: Nyquist plots of the MFCs with different bio-cathode (CP - carbon paper, GF - graphite felt and SSM - stainless steel mesh) [58].

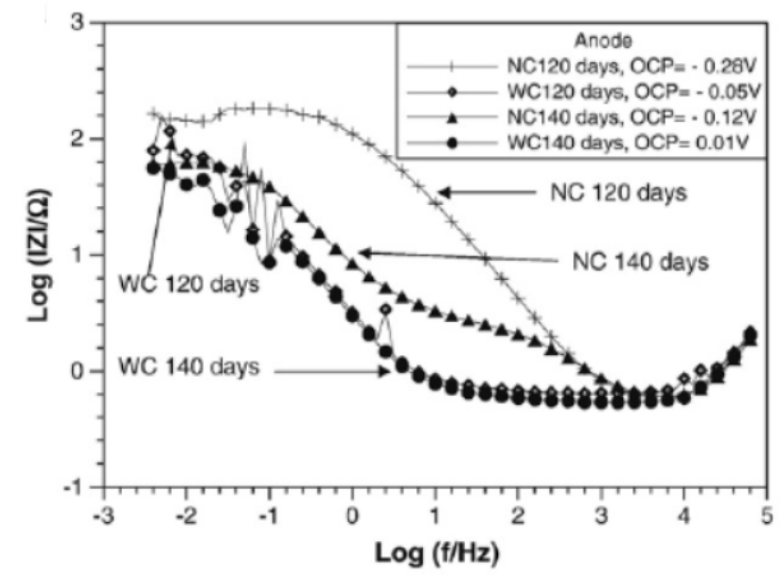

Figure 10: Bode plots of cathode impedance for MFCs with (NC) and without (WC) nafion [59].

system, both charge transfer resistance and the oxygen mass transfer are considered to be the major limiting factors for the performance of MFC [63]. In the case of bio-anode, maximum current is reached as a result of maximum in the biochemical conversion rate, whereas it is different for the case of bio-cathodes, the maximum current density is mainly limited by mass transfer, in addition to the charge transfer phenomenon due to the poor solubility of oxygen [62,63]. EIS has been proved to be a powerful tool for in depth analysis of bio-cathode behavior. The model used by Ter Heijne et al. [64] is a generalized Randles circuit with the finite length Warburg element for the diffusion transport of the reactant to the electrode surface. It has been concluded that fitting the impedance data at constant potential and different flow rates of oxygen had no effect on charge transfer resistance, but led to a decrease in mass transfer resistance with increasing flow rates as shown in Figure 11a. Such variation in the mass transfer resistance is mainly due to the diffusion limitation, which was overcome at higher flow rates. At the same time, the charge transfer resistance was found to be decreasing for the experiments conducted at varying cathode potential and constant flow rate as shown in Figure 11b. The distinct variation between the combined electrochemical-biochemical kinetics and the electrochemical kinetics alone has been studied using the EIS, which is very essential for characterizing the bio-cathodes. 

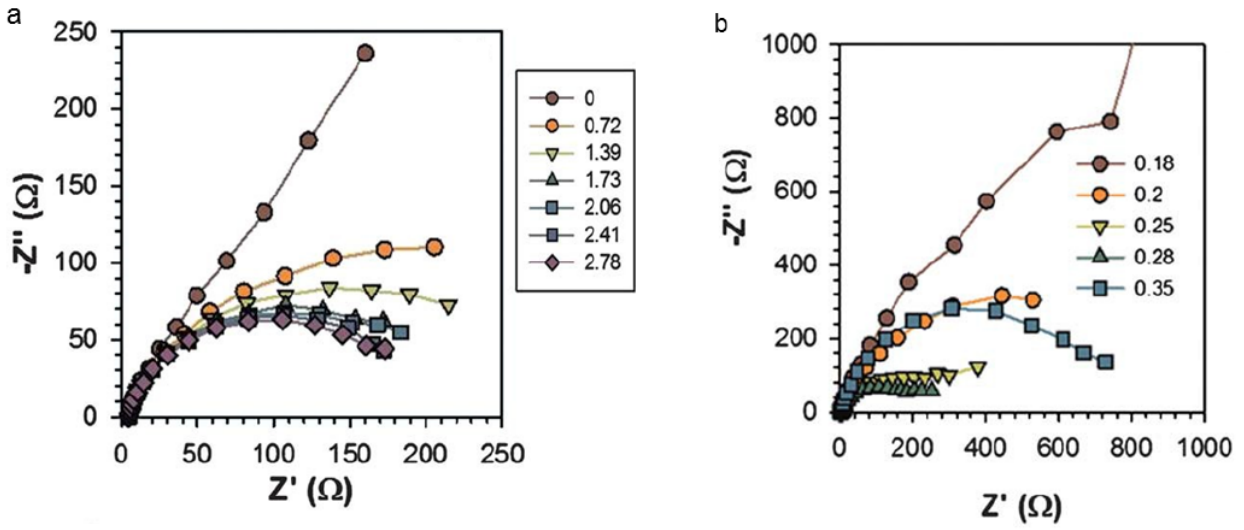

Figure 11: (a) Nyquist plots obtained for the bio-cathode at different flow rates and constant cathode potential $(0.28 \mathrm{~V}$ vs. Ag/ $\mathrm{AgCl})$ and (b) that at constant flow rate $(2.1 \mathrm{~cm} / \mathrm{s})$ and different cathode potentials [64].

\section{Full Cell Systems (Complete MFC Setup)}

\section{Effect of reactor configuration}

In the case of pilot scale MFCs, ohmic resistance has been observed to be predominant in the total internal resistances of the system [65], which is greatly dependent on the design and configuration of the MFC rather than the microbial population in the anode [11]. Almost $60 \%$ of the internal resistance has been contributed by the ohmic resistance in the MFC designed by You et al. [66]. Reducing the electrode spacing could be the most effective solution to reduce such larger ohmic resistance $[15,65]$. Recently design of up-flow MFCs has been adopted as an alternative approach, which when combined with the continuous operation resulted in relatively low internal resistances leading to greater power output $[22,40]$. You et al. [66] demonstrated that in a glucose fed up-flow air-cathode MFC, changing the sieve area from $30 \mathrm{~cm}^{2}$ to $60 \mathrm{~cm}^{2}$ resulted in increased power density mainly due to reduction in the overall internal resistance from $41 \Omega$ to $27.5 \Omega$ and decrease of ohmic resistance from $24.3 \Omega$ to $14 \Omega$ as shown in Figure 12 .

He et al. [22] developed a modified up-flow MFC with U-shaped cathode inside the anode chamber with a maximum volumetric power density of $29.2 \mathrm{~W} / \mathrm{m}^{3}$. It has been observed that the overall internal resistance was $17.13 \Omega$ at a volumetric loading rate of $3.40 \mathrm{~kg} \mathrm{COD} /\left(\mathrm{m}^{3}\right.$ Day) with the dominant component being the electrolyte resistance throughout the entire range of loading rates and both the anode and cathode charge transfer resistances were found to be important limiting factors for such design as shown in Figure 13. Further, a relatively smaller value for the diffusion resistance has showed that the transport limitation played a minor role compared to the ohmic and kinetic limitations. Based on these EIS analyses, further improvements were also suggested to improve the power density of the system.

Huang et al. [67] evaluate the electricity generating behavior of floating MFC operated for 153 days. With the help of EIS, it has been observed that the polarization resistance of the anode changed with the operating time, reaching a minimum at day 125 and correlated with the maximum power density production on that day. The polarization resistance of the cathode has been found to be relatively constant and much smaller compared to that of anode.

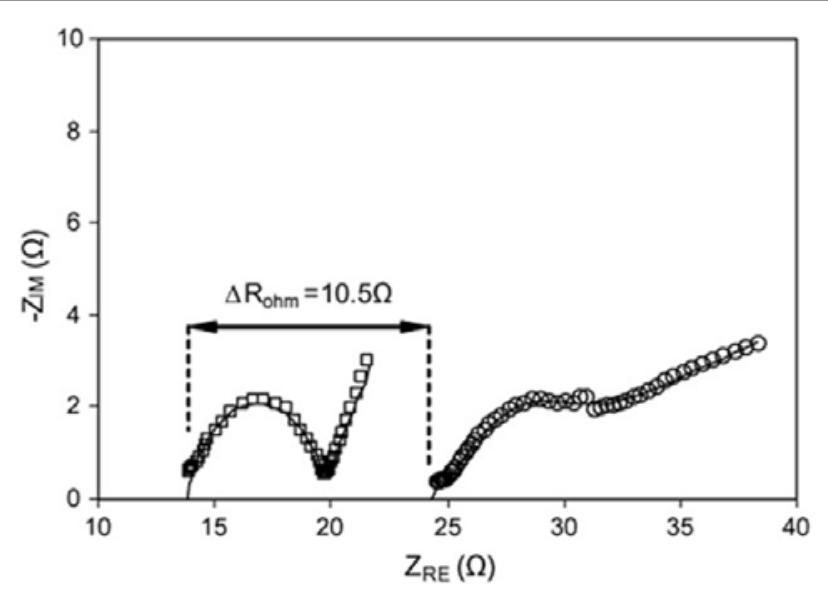

Figure 12: Nyquist plots of impedance spectra of MFCs with varying membrane area of $30 \mathrm{~cm}^{2}$ (circles) and $60 \mathrm{~cm} 2$ (squares) [67].

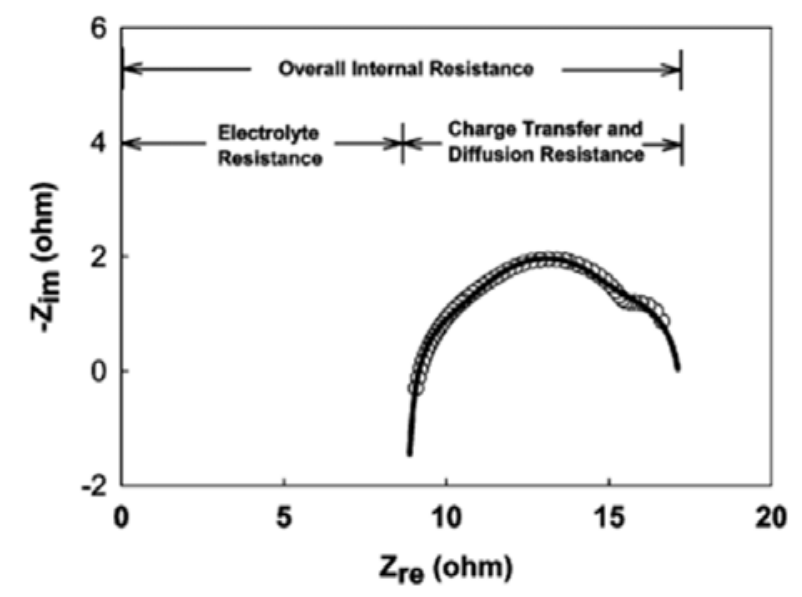

Figure 13: Nyquist plot of impedance spectra of up-flow MFC at the volumetric loading rate of $3.40 \mathrm{~kg} \mathrm{COD} /(\mathrm{m} 3$ day) [22].

\section{Effect of anode fluid ionic strength}

The ionic strength of the anolyte greatly influences the solution resistance, which in turn affects the power output of the MFC. Aaron 
et al. [68] used EIS to study the effect of the anode fluid ionic strength on the power output of air-cathode MFC. The individual resistive components have been analyzed by varying the ionic strength of the anolyte from $0.37 \mathrm{M}$ to $0.037 \mathrm{M}$. The Figure 14 shows the Nyquist plot of varying responses for the different ionic strengths examined and it has been clearly observed that both the total resistance as well as the solution resistance decrease on increasing the ionic strength. Approximately a reduction in one third of the solution resistance has been noticed (from $R_{\text {solution }}=3.79 \Omega$ at $37 \mathrm{mM}$ to $2.27 \Omega$ at $370 \mathrm{mM}$ ) [68]. Interestingly the $R_{a n}$ remained nearly unchanged, while the $R_{c a t}$ decreased markedly more than the reduction in $R_{\text {solution, }}$, which indicates the impedance of cathode impedance on the performance of aircathode MFC.

\section{Effect of separator}

The separators are generally used to prevent the electrodes from touching, short-circuiting and electrolytes to mix up. The anion or cation exchange membranes are usually used as separators to prevent the diffusion of oxygen into the anode chamber and to facilitate the movement of only protons across it to the cathode. The addition of separators reduces the power density by increasing the internal resistance and generates $\mathrm{pH}$ gradients between the anode and cathode. Wei et al. [69] used impedance spectroscopy to understand the impact of the separators on the performance of air-cathode MFC. It has been found that at a cathode potential of $0.3 \mathrm{~V}$, the average total resistance increased by $36 \%$ for $5 \mathrm{mM}$ PBS by the use of single separator and the total resistance was also three to five times larger for the system with four separators compared to the control without separator [69]. The diffusion resistance has been found to the major contributing factor in the varying internal resistances with only small changes in the solution resistance and the charge transfer resistance as shown in Figure 15, which suggested that the usage of separators hindered ion transport from the bulk to the cathode leading to mass transport limitations.

\section{Electron Transfer Mechanism of Exo-Electrogenic Microbes}

The different electron transfer mechanisms used by the exoelectrogenic bacteria such as Geobacter sulfurreducens and Shewanella oneidensis can be characterized using EIS. The electrochemical physiologies of these commonly used bacteria are very different. While G. sulfurreducens use conductive appendages called pili for their direct electron transfer onto the anode, S. oneidensis exploit the flavin mediators predominantly for the electron transfer. In both these micro-organisms the intracellular processes had higher values of impedance and capacitance compared to the extracellular processes [70], i.e., $80 \%$ of the total impedance has been contributed by the intracellular impedance $\left(R_{i n}\right)$ in G. sulfurreducens and $95 \%$ of the total impedance has been contributed by the $R_{i n}$ in $S$. oneidensis, indicating that the intracellular processes are rate limiting for their electrochemical electron transfer. Further, Jung has observed different impedance characteristics for both the bacteria [70]. The $R_{i n}$ and $R_{e x}$ of G. sulfurreducens were only $11 \%$ and $2-3 \%$ of that of S. oneidensis respectively, indicating that the electron transfer efficiency through the conductive pili by G. sulfurreducens is better than that of the flavin utilizing S. oneidensis. The diffusion of flavins through the membrane of $S$. oneidensis and their complex redox process has been found to be responsible for nearly 40 times larger electrical resistance and subsequent energetic loss, as dictated by their large $R_{e x}$ value. Figure 16 shows the different morphologies of high-frequency arcs in the Nyquist plot of MFC anode inoculated with G. sulfurreducens, S. oneidensis and

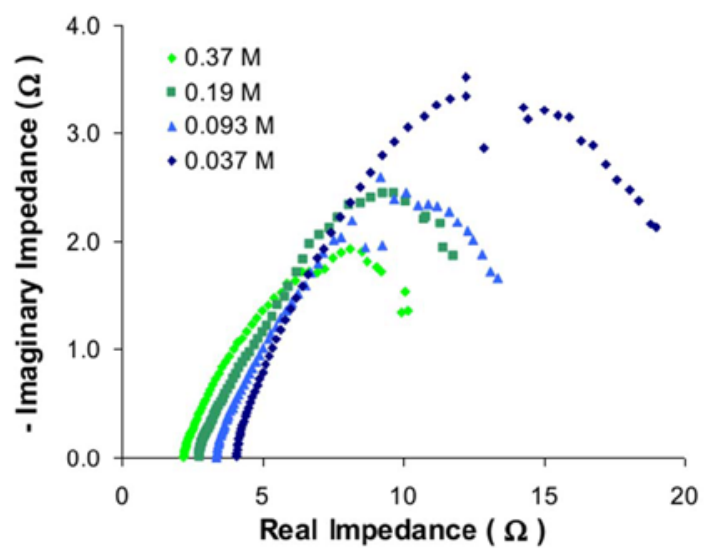

Figure 14: Nyquist plots of air-cathode MFC for varying anode fluid strength [69].

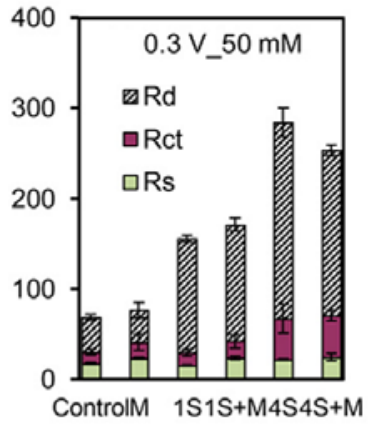

Figure 15: Component analysis of cathodes and separator electrode assemblies at $0.3 \mathrm{~V}$ in $50 \mathrm{mM}$ PBS. (Control - without separator, 1S - one separator, 4S - four separators, Rd - diffusion resistance, Rct - charge transfer resistance and Rs - solution resistance) [70].

their co-culture. A unique high-frequency arc consisting of two semi arcs has been observed for the co-culture. Also the high-frequency arcs of B were larger than those of A. These observations denote that the impedance spectra might be a useful tool to distinguish different exo-electrogenic electron transfer mechanisms. The charge transfer resistance $\left(R_{C T}\right)$ is inversely proportional to the exchange current $\left(I_{e x}\right)$ which in turn, is correlated to the kinetic rate constant $\left(k_{o}\right)$. Therefore the calculation of $R_{C T}$ from the EIS experiment can be used to deduce the kinetic rate of the processes limiting the electron transfer. Further, the use of EIS for mechanistic analysis has been briefly reviewed by Macdonald [71] with particular emphasis on mathematical techniques that are used to extract the kinetic data.

Particularly the electron transfer through redox active mediators can be investigated with the help of EIS. In such scenario, while classical approaches such as biochemical assays, HPLC or electrochemical technique such as $\mathrm{CV}$, require the regular sampling of the spent anolyte from the operating MFC, EIS provides an effective, non-intrusive and online analyses of the mediators secreted by the bacteria in the operating MFC without interfering with its performance [17,49,72]. Ramasamy et al. [42] exploited EIS as a tool to evaluate the extracellular mediators in a lactate-fed air breathing MFC harboring S. oneidensis DSP10 and attributed the observed Nyquist arc in the medium frequency region to the charge transfer impedance of the electron shuttle redox processes 


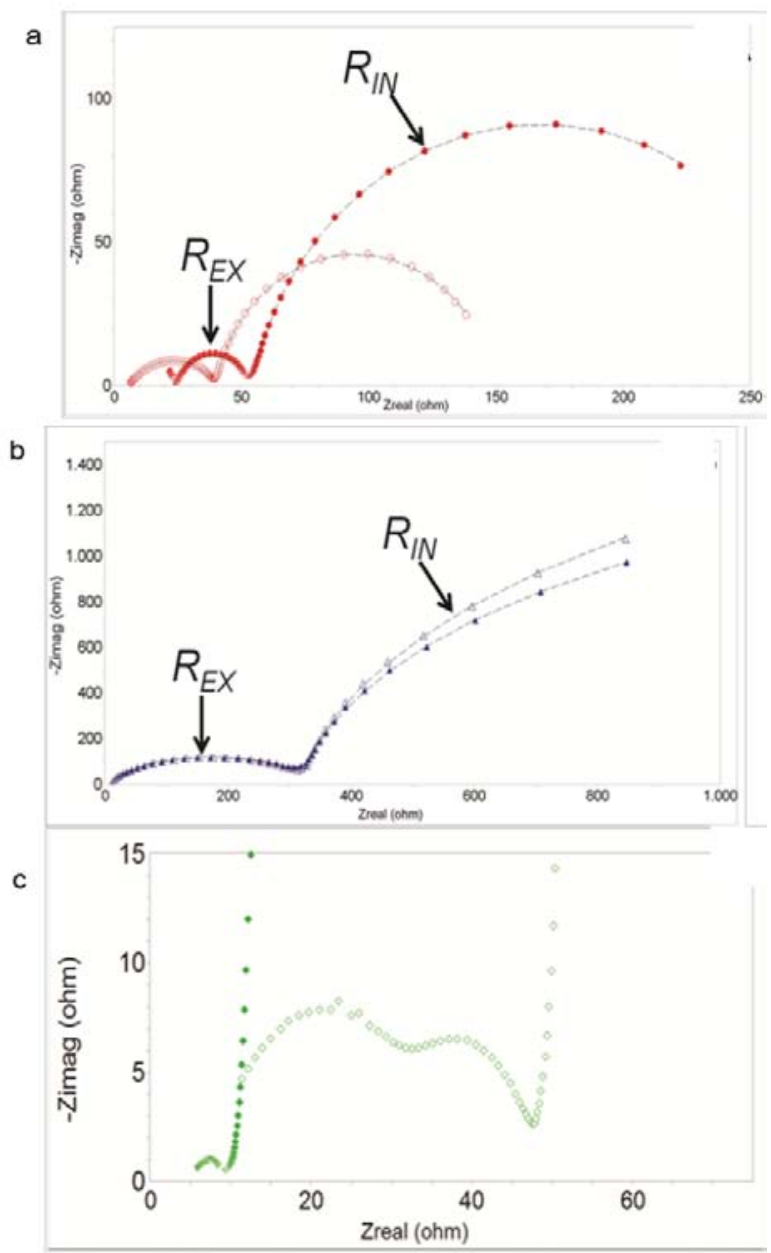

Figure 16: Nyquist plots of anode impedance for MFCs inoculated with (a) G. sulfurreducens, (b) S. oneidensis and (c) their co-culture [71].

on the anode. Thus EIS has also proven to be an effective tool for diagnosing the mediated electron transfer in MFC.

\section{Summary and Conclusions}

Electrochemical impedance spectroscopy has a greater potential to analyze and study the intricate impedance characteristics of microbial fuel cells. Moreover, the complex and highly non-linear biological system can be better optimized using such a semi-quantitative and highly effective tool. Particularly, the non-destructive way of measurements makes EIS, a fascinating tool for studying the MFC performance without disturbing its operation. Till date, this powerful technique has been successfully used by many researchers for the study of various resistance components and their contribution to overall internal impedance of MFCs. Many new designs, novel configurations and scaling-up of the MFC have already been in practice due to the enormous knowledge obtained from the measurement of impedance data. However, the EIS technique is still in its infant stage as mentioned in the former reviews, providing scope for further improvisation such as meaningful interpretation and validation of the model by correlating the calculated parameters to the measurable physical quantities, so that certain degree of standardization can be laid out. Further, the microscopic characteristics of the micro-organisms and their electron transfer mechanism can well be understood by combing EIS with other electrochemical techniques such as cyclic voltammetry, scanning electrochemical microscopy, etc. In conclusion, the knowledge of impedance from EIS alone is not sufficient, but combining the EIS with the other electrochemical and biochemical methodologies could better assist in understanding the performance of the bio-electrochemical systems.

\section{References}

1. Ramasamy RP (2012) Thylakoid based photosynthetic electrochemical cell. Gordon Research Conference on Photosynthesis.

2. Ramasamy RP (2012) Nanostructured photosystem complexes as biological fuel cell catalysts. AIChE Annual Meeting.

3. Ramasamy R (2012) Photosynthetic electrochemical cells. U.S. Provisional Patent filed on 08/03/2012. Serial No. 61/679,118.

4. Calkins JO, Umasankar Y, Ramasamy RP (2012) Photosynthetic energy conversion using thylakoid modified electrodes. Annual Meeting of the IBE.

5. Calkins JO, Umasankar Y, Ramasamy RP (2012) Manipulating photosynthesis for electricity generation. 4th Annual Georgia Nanotechnology and Infectious Diseases Symposium, Georgia.

6. Calkins JO, Umasankar Y, Ramasamy RP (2012) Photo-electrochemical activity of thylakoids on carbon nanotube modified electrodes. 221st Meeting of the ECS.

7. Calkins JO, Umasankar Y, Ramasamy RP (2013) High photo-electrochemica activity of thylakoid-carbon nanotube composites for photosynthetic energy conversion. Energy Environ Sci 6: 1891-1900.

8. Rabaey K, Rozendal RA (2010) Microbial electrosynthesis - revisiting the electrical route for microbial production. Nat Rev Microbiol 8: 706-716.

9. He Z, Mansfeld F (2009) Exploring the use of electrochemical impedance spectroscopy (EIS) in microbial fuel cell studies. Energy Environ Sci 2: 215.

10. Dominguez-Benetton X, Sevda S, Vanbroekhoven K, Pant D (2012) The accurate use of impedance analysis for the study of microbial electrochemical systems. Chem Soc Rev 41: 7228-7246.

11. Logan BE, Regan JM (2006) Microbial fuel cells--challenges and applications. Environ Sci Technol 40: 5172-5180

12. Franks AE, Nevin KP (2010) Microbial Fuel Cells, A Current Review. Energies 3: 899-919.

13. Lovley DR (2006) Microbial fuel cells: novel microbial physiologies and engineering approaches. Curr Opin Biotechnol 17: 327-332

14. Rabaey K, Rodríguez J, Blackall LL, Keller J, Gross P, et al. (2007) Microbia ecology meets electrochemistry: electricity-driven and driving communities. ISME J 1: 9-18.

15. Liu H, Cheng SA, Logan BE (2005) Power generation in fed-batch microbial fuel cells as a function of ionic strength, temperature, and reactor configuration. Environ Sci Technol 39: 5488-5493.

16. Logan BE, Hamelers B, Rozendal R, Schröder U, Keller J, et al. (2006) Microbia fuel cells: methodology and technology. Environ Sci Technol 40: 5181-5192.

17. Roy JN, Luckarift HR, Lau C, Falase A, Garcia KE et al. (2012) A study of the flavin response by Shewanella cultures in carbon-limited environments. RSC Advances 2: 10020-10027.

18. Kelly RG, Sculy JR, Shoesmith D, Buchheit RG (2002) Electrochemical techniques in corrosion science and engineering (1st edn.), CRC Press.

19. Huet $F$ (1998) A review of impedance measurements for determination of the state-of-charge or state-of-health of secondary batteries. J Power Sour 70: 5969.

20. Wagner N, Schnurnberger W, Muller B, Lang M (1998) Electrochemical impedance spectra of solid-oxide fuel cells and polymer membrane fuel cells. Electrochimica Acta 43: 3785-3793.

21. Cheung ACM, Bretschger O, Mansfeld F, Nealson KH (2007) FUEL 127-Performance of different strains of the senus Shewanella in a microbia fuel cell. Am Chem Soc 234.

22. He Z, Wagner N, Minteer SD, Angenent LT (2006) An upflow microbial fuel cel 
Citation: Sekar N, Ramasamy RP (2013) Electrochemical Impedance Spectroscopy for Microbial Fuel Cell Characterization. J Microb Biochem Technol S6: 004. doi:10.4172/1948-5948.S6-004

Page 13 of 14

with an interior cathode: assessment of the internal resistance by impedance spectroscopy. Environ Sci Technol 40: 5212-5217.

23. Orazem ME, Tribollet B (2008) Electrochemical Impedance Spectroscopy. John Wiley \& Sons Inc.

24. Barsoukov E, Macdonald JR (2005) Impedance Spectroscopy: Theory, Experiment, and Applications (2nd edn.) John Wiley \& Sons Inc.

25. Park SM, Yoo JS (2003) Electrochemical impedance spectroscopy for better electrochemical measurements. Anal Chem 75: 455A-461A

26. Bard AJ, Faulkner LR (2001) Electrochemical Methods: Fundamentals and Applications (2nd edn.) John Wiley \& Sons Inc.

27. Scully JR, Silverman DC, Kendig MW (1993) Electrochemical impedance: Analysis and interpretation, ASTM International.

28. Laurent F, Grosgogeat B, Reclaru L, Dalard F, Lissac M (2001) Comparison of corrosion behaviour in presence of oral bacteria. Biomaterials 22: 2273-2282.

29. David L, Nelson MMC (2008) Lehninger Principles of Biochemistry (4thedn.) Palgrave Macmillan.

30. Basics of Electrochemical Impedance Spectroscopy.

31. Malvankar NS, Mester T, Tuominen MT, Lovley DR (2012) Supercapacitors based on c-type cytochromes using conductive nanostructured networks of living bacteria. Chemphyschem 13: 463-468

32. Hilbert LR (2000) Monitoring Microbially Influenced Corrosion. PhD Thesis, Technical University of Denmark.

33. Domínguez-Benetton X (2007) Biocomplexity and Electrochemical Influence of Biofilms in Carbon Steel Deterioration in Gasoline-Containing Environments: A Transmission Line Approach for Electrochemical Impedance Analysis. PhD Thesis, Instituto Mexicano del Petróleo.

34. Chang BY, Park SM (2010) Electrochemical impedance spectroscopy. Annu Rev Anal Chem (Palo Alto Calif) 3: 207-229

35. Liang P, Huang X, Fan MZ, Cao XX, Wang C (2007) Composition and distribution of internal resistance in three types of microbial fuel cells. Appl Microbiol Biotechnol 77: 551-558.

36. Liu H, Ramnarayanan R, Logan BE (2004) Production of electricity during wastewater treatment using a single chamber microbial fuel cell. Environ Sci Technol 38: 2281-2285

37. Min B, Logan BE (2004) Continuous electricity generation from domestic wastewater and organic substrates in a flat plate microbial fuel cell. Environ Sci Technol 38: 5809-5814.

38. Oh S, Min B, Logan BE (2004) Cathode performance as a factor in electricity generation in microbial fuel cells. Environ Sci Technol 38: 4900-4904.

39. Min B, Cheng S, Logan BE (2005) Electricity generation using membrane and salt bridge microbial fuel cells. Water Res 39: 1675-1686.

40. Rabaey K, Clauwaert P, Aelterman P, Verstraete W (2005) Tubular microbia fuel cells for efficient electricity generation. Environ Sci Technol 39: 8077-8082.

41. Ramasamy RP, Ren Z, Mench MM, Regan JM (2008) Impact of initial biofilm growth on the anode impedance of microbial fuel cells. Biotechnol Bioeng 101 101-108.

42. Ramasamy RP, Gadhamshetty V, Nadeau LJ, Johnson GR (2009) Impedance spectroscopy as a tool for non-intrusive detection of extracellular mediators in microbial fuel cells. Biotechnol Bioeng 104: 882-891.

43. Ren Z, Ramasamy RP, Cloud-Owen SR, Yan H, Mench MM, et al. (2011) Time-course correlation of biofilm properties and electrochemical performance in single-chamber microbial fuel cells. Bioresour Technol 102: 416-421.

44. Manohar AK, Bretschger O, Nealson KH, Mansfeld F (2008) The use of electrochemical impedance spectroscopy (EIS) in the evaluation of the electrochemical properties of a microbial fuel cell. Bioelectrochem 72: 149-154.

45. Borole AP, Hamilton CY, Aaron DS, Tsouris C (2009) Investigating microbia fuel cell bioanode performance under different cathode conditions. Biotechno Prog 25: 1630-1636.

46. He Z, Huang Y, Manohar AK, Mansfeld F (2008) Effect of electrolyte pH on the rate of the anodic and cathodic reactions in an air-cathode microbial fuel cell. Bioelectrochem 74: 78-82.
47. Borole AP, Aaron D, Hamilton CY, Tsouris C (2010) Understanding long-term changes in microbial fuel cell performance using electrochemical impedance spectroscopy. Environ Sci Technol 44: 2740-2745.

48. Kim T, Kang J, Lee JH, Yoon J (2011) Influence of attached bacteria and biofilm on double-layer capacitance during biofilm monitoring by electrochemical impedance spectroscopy. Water Res 45: 4615-4622.

49. von Canstein H, Ogawa J, Shimizu S, Lloyd JR (2008) Secretion of flavins by Shewanella species and their role in extracellular electron transfer. App Environ Microbiol 74: 615-623.

50. Gorby Y, McLean J, Korenevsky A, Rosso K, El-Naggar MY, et al. (2008) Redox-reactive membrane vesicles produced by Shewanella. Geobiology 6 : 232-241.

51. Marsili E, Baron DB, Shikhare ID, Coursolle D, Gralnick JA, et al. (2008) Shewanella secretes flavins that mediate extracellular electron transfer. Proc Natl Acad Sci U S A 105: 3968-3973.

52. Gil GC, Chang IS, Kim BH, Kim M, Jang JK, et al. (2003) Operationa parameters affecting the performannce of a mediator-less microbial fuel cell. Biosens Bioelectron 18: 327-334

53. He Z, Shao H, Angenent LT (2007) Increased power production from a sediment microbial fuel cell with a rotating cathode. Biosens Bioelectron 22: 3252-3255.

54. Oh SE, Logan BE (2006) Proton exchange membrane and electrode surface areas as factors that affect power generation in microbial fuel cells. App Microbiol Biotechnol 70: 162-169.

55. Lepage G, Albernaz FO, Perrier G, Merlin G (2012) Characterization of a microbial fuel cell with reticulated carbon foam electrodes. Bioresour Technol 124: 199-207.

56. Kim JR, Premier GC, Hawkes FR, Dinsdale RM, Guwy AJ (2009) Development of a tubular microbial fuel cell (MFC) employing a membrane electrode assembly cathode. J Power Sour 187: 393-399.

57. Martin E, Tartakovsky B, Savadogo O (2011) Cathode materials evaluation in microbial fuel cells: A comparison of carbon, $\mathrm{Mn}_{2} \mathrm{O}_{3}, \mathrm{Fe}_{2} \mathrm{O}_{3}$ and platinum materials. Electrochimica Acta 58: 58-66.

58. Zhang Y, Sun J, Hu Y, Li S, Xu Q (2012) Bio-cathode materials evaluation in microbial fuel cells: A comparison of graphite felt, carbon paper and stainless steel mesh materials. International Journal of Hydrogen Energy 37: 1693516942.

59. Huang $Y$, He Z, Mansfeld F (2010) Performance of microbial fuel cells with and without Nafion solution as cathode binding agent. Bioelectrochem 79: 261-264.

60. Hamelers HV, Ter Heijne A, Sleutels TH, Jeremiasse AW, Strik DP, et al. (2010) New applications and performance of bioelectrochemical systems. App Microbiol Biotechnol 85: 1673-1685.

61. Clauwaert P, Van der Ha D, Boon N, Verbeken K, Verhaege M, et al. (2007) Open air biocathode enables effective electricity generation with microbial fue cells. Environ Sci Technol 41: 7564-7569.

62. Freguia S, Tsujimura S, Kano K (2010) Electron transfer pathways in microbial oxygen biocathodes. Electrochimica Acta 55: 813-818.

63. Ter Heijne A, Strik DP, Hamelers HV, Buisman CJ (2010) Cathode potentia and mass transfer determine performance of oxygen reducing biocathodes in microbial fuel cells. Environ Sci Technol 44: 7151-7156.

64. Ter Heijne A, Schaetzle O, Gimenez S, Fabregat-Santiago F, Bisquert J et al. (2011) Identifying charge and mass transfer resistances of an oxygen reducing biocathode. Energy Environ Sci 4: 5035

65. Barbir F (2005) PEM Fuel Cells: Theory and Practice, Academic Press.

66. You S, Zhao Q, Zhang J, Liu H, Jiang J, et al. (2008) Increased sustainable electricity generation in up-flow air-cathode microbial fuel cells. Biosens Bioelectron 23: 1157-1160.

67. Huang Y, He Z, Kan J, Manohar AK, Nealson KH, et al. (2012) Electricity generation from a floating microbial fuel cell. Bioresour Technol 114: 308-313.

68. Aaron D, Tsouris C, Hamilton CY, Borole AP (2010) Assessment of the Effects of Flow Rate and lonic Strength on the Performance of an Air-Cathode Microbial Fuel Cell Using Electrochemical Impedance Spectroscopy. Energies 3: 592-606.

69. Wei B, Tokash JC, Zhang F, Kim Y, Logan B E (2013) Electrochemical 
Citation: Sekar N, Ramasamy RP (2013) Electrochemical Impedance Spectroscopy for Microbial Fuel Cell Characterization. J Microb Biochem Technol S6: 004. doi:10.4172/1948-5948.S6-004

Page 14 of 14

analysis of separators used in single-chamber, air-cathode microbial fuel cells. Electrochimica Acta 89: 45-51.

70. Jung S (2012) Impedance Analysis of Geobacter sulfurreducens PCA, Shewanella oneidensis MR-1, and their Coculture in Bioeletrochemical Systems. International Journal of Electrochemical Science 7: 11091-11100.
71. Macdonald DD (1990) Review of mechanistic analysis by electrochemical impedance spectroscopy. Electrochimica Acta 35: 1509-1525.

72. Biffinger JC, Pietron J, Bretschger O, Nadeau LJ, Johnson GR, et al. (2008) The influence of acidity on microbial fuel cells containing Shewanella oneidensis. Biosens Bioelectron 24: 906-911.

This article was originally published in a special issue, Biofuel Cells and Bioelectrochemical systems handled by Editor(s). Abhijeet P Borole, Oak Ridge National Laboratory, USA; Justin C Biffinger, US Naval Research Laboratory, USA 